\title{
Effect of Preparation Parameters on Methylene blue number of Activated Carbons Prepared from a Locally Available Material
}

\author{
Rajeshwar Man Shrestha \\ Department of Engineering Science and Humanities, Institute of Engineering, Tribhuvan University, Nepal \\ Corresponding author: rajeshwar@ioe.edu.np
}

Received: July 24, 2016 Revised: Aug 5, 2016 Accepted: Aug. 20, 2016

\begin{abstract}
The adsorption of Methylene blue by the activated carbons prepared from a locally available material Lapsi Seed Stone has been studied. Various activated carbons were prepared by varying the parameters such as ratio of Lapsi seed stone particles to Phosphoric acid, carbonization temperature and carbonization time. Determination of Methylene blue numbers of the activated carbons was done by single point method by batch mode. Methylene blue number is found to be affected by the various preparation conditions like carbonization temperature, carbonization time, ratio of activating agent and Lapsi seed stone particles and the concentration of phosphoric acid. The optimum conditions for the preparation of activated carbon are found to be carbonization temperature 400 ${ }^{\circ} \mathrm{C}$ for 4 hours at the ratio of 1:1 Lapsi seed stone particles and Phosphoric acid.
\end{abstract}

Keywords: Lapsi seed stone, Activated carbon, Adsorption, Methylene blue, Methylene blue number

\section{Introduction}

Activated carbons are porous materials of great importance since they are widely in the adsorption of pollutants in gaseous phase or liquid phase, gases storage. There are a quite large number of studies regarding the preparation of activated carbons from agriculture wastes, fruit stones, hard shell of fruit stones, bagasse, manure compost, oil palm waste, agriculture residue from sugarcane, saw dust, sewage sludge [8]. Most of activated carbons are prepared by a two- stage process carbonization followed by activation. The first step is to enrich the carbon content and to create an initial porosity and activation process helps in enhancing the pore structure. The activation can be carried by two different processes physical and chemical. Chemical activation has two important advantages as compared to physical activation. One is lower temperature in which the process is accomplished. The other is that the global yield to the chemical activation tends to be greater since burn off char is not required.

The use of low cost wastes and agricultural by- products for production of activated carbon has been shown to provide economic solution. Many precursors have been used with success for the production of activated carbons including apricot stones [6] guava seeds [3] black stone cherries [7], peach stones [1, 4], orange peel [5], Peanut shell [13] which are the some examples of low- 
cost accessible raw materials for the production of Activated carbons. Lapsi seed stone is the waste product of Lapsi fruits. Lapsi (Choerospondias axillaris) belongs to the family Anacardiaceous. It is a large, fruit bearing deciduous tree native to the hills of Nepal $(865-1900 \mathrm{~m})$. Lapsi fruit is consumed fresh, pickled or processed into a variety of sweet and sour fruit products locally called "Mada" or "Titaura". It is a rich source of vitamin C. It is also believed to aid in digestion and is often consumed after a protein rich meal. Seed stones are used as fuel in brick kilns in the factories and the trunk of the tree is used as fuel wood and timber $[9,10]$. Iron impregnated activated carbon prepared from Lapsi seed stone had been investigated for the removal of arsenic from water [11]. Not much information is available regarding the preparation of activated carbon from Lapsi seed stone using phosphoric acid as an activating agent. Activated carbon was prepared from Lapsi seed stone by chemical activation with zinc chloride for the adsorption of arsenic from water. No report is available in the literature about the preparation of activated carbon from Lapsi seed stone using phosphoric acid as an activating agent. This lack in existing literature is a motivation for the present study.

Activated carbons are usually characterized by several physical parameters such as surface area and pore volume. The surface areas of activated carbons are usually measured using the BrunauerEmmett-Teller (BET) method, which employs the nitrogen adsorption at different pressures at the temperature of liquid nitrogen $(77 \mathrm{~K})$. The surface area according to BET is then determined by the product of the cross-sectional area of the nitrogen molecule, of the Avogadro's number and of the specific monolayer capacity of nitrogen, which is obtained by an equation proposed by BET with further modifications. For the pore volume determination, the procedure more commonly used also uses nitrogen adsorption isotherm data. The total pore volume is estimated from the amount of nitrogen adsorbed at the highest relative pressure and the micropore volume is calculated from the nitrogen adsorption isotherms using the Dubinin-Radushkevich equation. In spite of these methods being more used and employed as a reference in the surface area and pore volume determination of porous materials, they are time consuming and require the use of expensive equipment.

Additional information about the structure of activated carbons can be obtained by the adsorption characteristics of different adsorbates, such as methylene blue and iodine. Methylene blue is a synthetic cationic thiazine dye of an amorphous nature with a molecular formula $\mathrm{C}_{16} \mathrm{H}_{18} \mathrm{ClN}_{3} \mathrm{~S} \cdot \mathrm{XH}_{2} \mathrm{O}$. It is also called basic blue 9, tetramethylthionine chloride. It is a dark green powder, with a characteristic deep blue color in aqueous solution where it dissociates into an MB cation and a chloride anion [2].

The methylene blue number is defined as the maximum amount of dye adsorbed on $1.0 \mathrm{~g}$ of adsorbent. Adsorption experiments of the molecules of methylene blue are easy and habitually done to characterize activated carbons with the purpose of obtaining information on the adsorption capacity of the materials. According to the dimensions of the methylene blue molecule, it is mainly adsorbed in mesopores, however, a small portion is also found in larger micropore. The aim of this investigation is to determine methylene blue number of activated carbons prepared from Lapsi seed stone by chemical activation with Phosphoric acid. 


\section{Material and Methods}

\subsection{Preparation of Adsorbent}

Seed stones of Lapsi fruits are the precursors used for the preparation of activated carbon in this study.Lapsi fruits were collected from Kalimati market, Kalimati, Kathmandu. The fruits were stripped for the pulp by boiling to expose rigid centers or stones. The seed stones were washed several times using tap water and then distilled water to remove impurities, dried at $110^{\circ} \mathrm{C}$ for 24 hours and crushed with mortar and grinded with electric grinder. The crushed particles were then sieved to obtain the fraction $300 \mu \mathrm{m}$. The particles were mixed with $50 \% \mathrm{H}_{3} \mathrm{PO}_{4}$ in the ratio of $1: 1$ and dehydrated at $100{ }^{\circ} \mathrm{C}$ for 24 hours in a hot box oven and then carbonized at $400{ }^{\circ} \mathrm{C}$ for four hours in a horizontal tubular furnace under flow $(75 \mathrm{ml} / \mathrm{min})$ nitrogen. The resultant activated carbon was cooled at room temperature and was washed several times with hot distilled water. The material was then dried at $110{ }^{\circ} \mathrm{C}$ for 24 hours, cooled and sieved to obtain the particles of size $106 \mu \mathrm{m}$.

\subsection{Chemical and Instrument}

Methylene blue used was of analytical grade (Qualigens Company). The adsorption experiments were carried out by using Shaker (Digital VDRL Rotator-RPM-S). All the working solutions were prepared by diluting the stock solutions with distilled water.

\subsection{Adsorption Experiments}

In order to determine the methylene blue number of activated carbons $0.05 \mathrm{~g}$ of activated carbon were stirred with $100 \mathrm{~mL}$ of MB concentration of $100 \mathrm{ppm}$ for 3 hours at $200 \mathrm{rpm}$. The solution was then filtered through Whatman 41 filter paper and the remaining concentration of methylene blue was determined by measuring the absorbance at $664 \mathrm{~nm}$ using a UV/Visible spectrophotometer (CECIL- CE-100).

Methylene blue number was calculated by the following equation [12]

$$
\mathrm{MB}_{\mathrm{N}}(\mathrm{mg} / \mathrm{g})=\frac{\left(\mathrm{C}_{\mathrm{o}}-\mathrm{C}_{\mathrm{e}}\right) \times \mathrm{V}}{\mathrm{M}}
$$

Where Co and Ce are initial and equilibrium concentration of MB (mg / L) respectively, $\mathrm{M}$ is the mass of adsorbent in gram $(\mathrm{g})$ and $\mathrm{V}$ is the volume of the solution in liter $(\mathrm{L})$ and $\mathrm{MB}_{\mathrm{N}}$ is Methylene blue number.

\section{Results and Discussion}

Activated carbons were prepared from Lapsi (Choerospondias axillaris) seed stone by chemical activation with hosphoric acid. The resultant carbons were characterized by Methylene blue number. Effect of various preparation parameters like ratio of Lapsi Seed Stone to Phosphoric acid, concentration of the acid, carbonization time and carbonization temperature was studied. 


\subsection{Effect of Carbonization temperature and carbonization time}

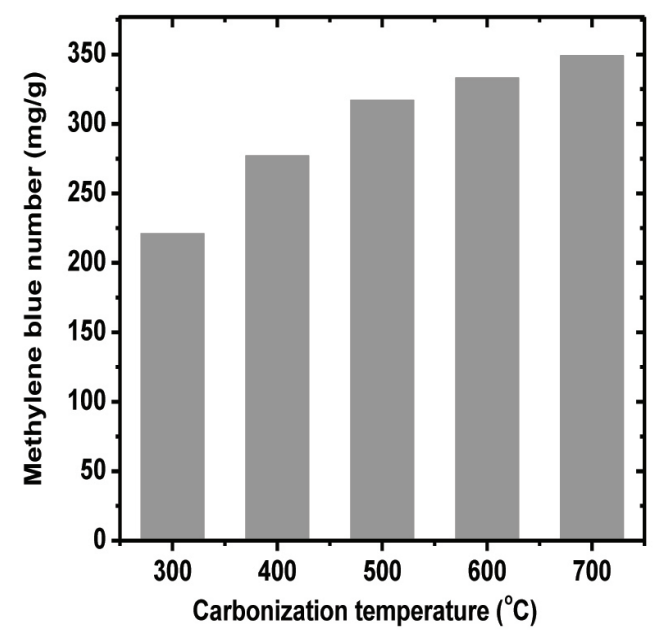

Fig. 3.1: Effect of carbonization temperature on methylene blue number of activated carbons

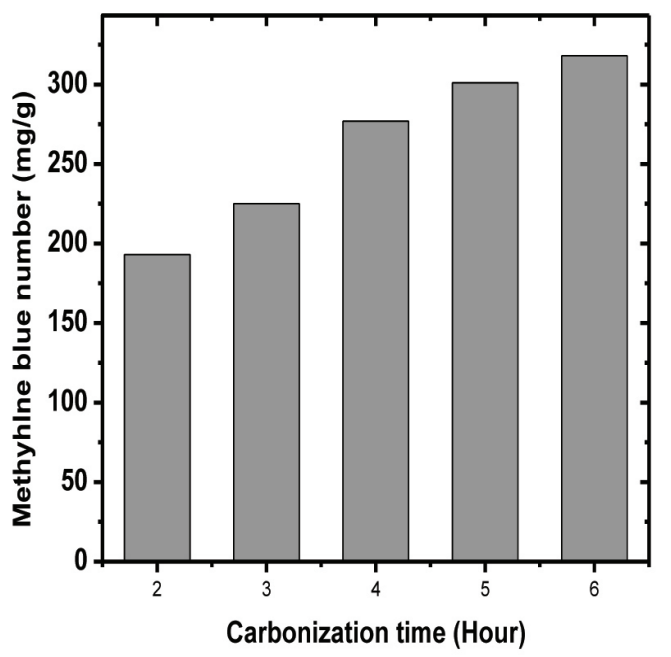

Fig. 3.2: Effect of carbonization time on methylene blue number of activated carbons

The variation of methylene blue number of activated carbons as a function of carbonization temperature keeping other parameters such as impregnation ratio, carbonization time and concentration of phosphoric acid constant is shown in Fig. 3.1. From which it is clear methylene blue number increases up to $500^{\circ} \mathrm{C}$ and then after the variation of methylene number is insignificant. The increase in methylene blue number from $300{ }^{\circ} \mathrm{C}$ to $400{ }^{\circ} \mathrm{C}$ is more significant than that in 500 ${ }^{\circ} \mathrm{C}$. Methylene blue number indicates mesopore distribution in the activated carbon. The results indicate that the carbonization temperature has a significant effect in the pore structure of activated carbon which ultimately determines the adsorption capacity of activated carbon. The highest value of methylene blue number is obtained at $700{ }^{\circ} \mathrm{C}$. This may be due to the widening of some micropores caused by escaping out of more volatile matters at high temperature.

The effect of carbonization time on methylene number of the activated carbons keeping other parameters like impregnation ratio, carbonization temperature and concentration of phosphoric acid constant is shown in Fig. 3.2. The methlylene blue number increases with carbonization time up to 4 hours and then after the increase in methlylene blue number occurs slowly. The slow increase of methylene blue may be due to the widening of micropores resulting in the formation of mesopores.From this result one may conclude that 4 hours of carbonization at $400{ }^{\circ} \mathrm{C}$ is necessary to prepare the activated carbon with high methylene blue number. 


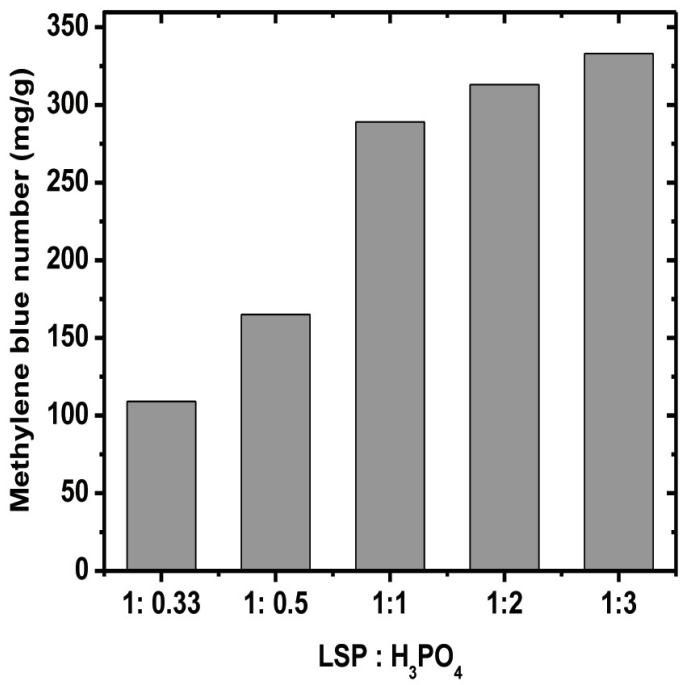

Fig. 3.3: Effect of LSSP: $\mathrm{H}_{3} \mathrm{PO}_{4}$ on methylene number of activated carbons

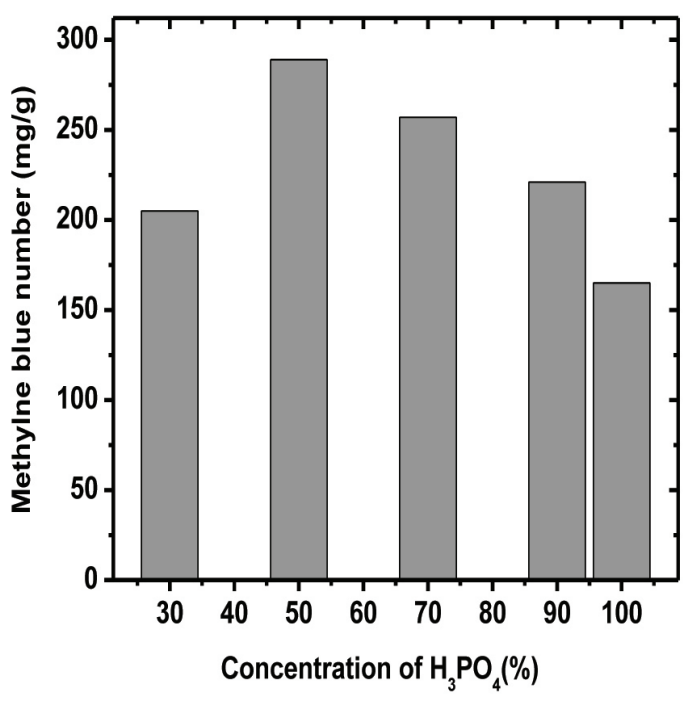

Fig. 3.4: Effect of concentration of $\mathrm{H}_{3} \mathrm{PO}_{4}$ on methylene number of activated carbons

\subsection{Effect of Ratio of Lapsi Seed Stone Powder: $\mathrm{H}_{3} \mathrm{PO}_{4}$ and Concentration of}

\section{Phosphoric acid}

The variation of methylene number of the activated carbons prepared at different LSSP: $\mathrm{H}_{3} \mathrm{PO}_{4}$ ratio keeping constant other parameters is shown in Fig. 3.3. The methylene number of activated carbons increases with the increase in amount of acid and after 1:1 ratio the increase is not significant. This may be due to the degeneration of pores caused by excessive dehydration with more acid.

Methylene number of the carbons prepared by activation with different concentration of $\mathrm{H}_{3} \mathrm{PO}_{4}$ keeping other parameters constant is shown in Fig. 3.4. When the concentration of $\mathrm{H}_{3} \mathrm{PO}_{4}$ increases from $30 \%$ to $50 \% \mathrm{H}_{3} \mathrm{PO}_{4}$ methylene number increases significantly and then after it decreases gradually. The decrease in methylene blue number at high concentration of phosphoric acid may be caused by degeneration of porous structures of activated carbons due to excessive dehydration.

\section{Conclusion}

The determination of Methylene blue number is the simple and quick method to characterize activated carbons. Procedures used in the determination of methylene blue number is relatively cheap and simple and do not require the use of sophisticated equipment. Although this method does not substitute the proper characterization of the textural properties for activated carbons, it is valuable for laboratories in which the equipment for gas adsorption experiments is not available. The methylene blue number is affected by the various preparation conditions such as carbonization temperature, carbonization time, the ratio of Lapsi seed stone particles and Phosphoric acid and the concentration of phosphoric acid. The optimum conditions for the preparation of activated carbon from Lapsi seed stone are $400{ }^{\circ} \mathrm{C}$ - the carbonization temperature, 4 Hours- the carbonization time, 1:1 - the ratio of Lapsi seed stone particles and Phosphoric acid. 
174 Effect of Preparation Parameters on Methylene blue number of Activated carbons Prepared from a ...

\section{References}

[1] Amina AA, Badie SG and Nady AF (2008), Removal of methylene blue by carbons derived from peach stones by $\mathrm{H}_{3} \mathrm{PO}_{4}$ activation: Batch and column studies, Dyes and Pigments, 76:282-289.

[2] Atef S and ALzaydien (2009), Adsorption of Methylene blue from Aqueous Solution onto a Low-cost Natural Jordanion Tripoli, American Journal of Environmental Sciences 5: 197-208.

[3] Collin GJ, Awanf B Duduku K and Kok Onn S (2007), Sorption studies of Methylene Blue Dye in aqueous solution by Optimized Carbon Prepared from Guava Seeds(Psidium guajava L) Materials Science, 13: 83-87.

[4] Dong SK (2004), Activated Carbon from Peach Stones Using Phosphoric Acid Activation at Medium Temperatures, Journal of Environmental Science and Health, 39: 1301-1318.

[5] Foo KY and Hameed B, (2002), Preparation, Characterization and evaluation of adsorptive properties of orange peel based activated carbon via microwave induce $\mathrm{K}_{2} \mathrm{CO}_{3}$ activation, Bioresource Technology, 104: 679- 689.

[6] Lotfi M, Djoudi M, Abdelkrim B and Lazhar B (2011), Adsorption of Pb(II) from aqueous solutions using activated carbon developed from Apricot stone, Desalination, 276: 148-153.

[7[ Maria JR Arana R and Mazzoco RR (2010), Adsorption studies of methylene blue and phenol onto black stone cherries prepared by chemical activation, Journal of Hazardous Maetrials, 180: 656-661.

[8] Mohammadi SZ Karimi MA, Afzali D and Mansouri F (2010), Removal of Pb (II) ions from aqueous Solution using activated carbon from Sea buckthorn by chemical activation, Desalination, 263: 83-93

[9] Paudel KC and Parajuli DP (1999), Domestication and Commercialization of Lapsi tree: potential income source through agroforestry in the middle hills of Nepal. In Ministry of Science and Technology, Scientific World, Nepal 1: 116-120.

[10] Paudel KC, Pieber K, Klumpp R and Laimer M(2003), Evaluation of Lapsi tree (Choerospondias axillaris, Roxb.) for fruit production in Nepal

[11] Rajbhandari R, Shrestha LK and Pradhananga RR (2012), Nanoporous Activated Carbon Derived from Lapsi (Choerospondias axillaris) Seed Stone for the Removal of Arsenic from water, Journal of Nanoscience and Nanotechnology, 12: $7002-7009$

[12] Raposo F De La Rubia MA and Borja R (2009), Methylene blue number as useful indicator to evaluate the adsorptive capacity of granular activated carbon in batch mode: Influence of adsorbate/adsorbent mass ratio and particle size, Journal of Hazardous Materials, 165: 291-299.

[13] Tau X and Xiaoqin L (2008), Peanut shell Activated Carbon: Characterization, Surface Modification and Adsorption of $\mathrm{Pb}^{+2}$ from Aqueous Solution, Chinese Journal of Chemical Engineering, 16: 401- 406. 